\title{
Optimization and Effect of Process Parameters on Tool Wear in Turning of Titanium Alloy under Different Machining Conditions
}

\author{
M. Venkata Ramana, G. Krishna Mohan Rao, and D. Hanumantha Rao
}

\begin{abstract}
To obtain safe, environmental and economical benefits of machining, the research has been carrying out to reduce the use of cutting fluid during machining. One of the alternatives to dry and flooded machining is Minimum Quantity Lubrication from the point of cost, ecology and human health issues. This paper deals with the optimization of process parameters in turning of Titanium alloy (Ti-6Al-4V) under different machining conditions using Taguchi's Robust Design Methodology on tool wear. The control factors selected are type of machining environment, cutting speed, feed rate, depth of cut and type of carbide tool material. From Analysis of Means, it is found MQL and uncoated tool shown in better performance on reduction of tool wear rate. From the Analysis of Variance (ANOVA), it is found that the cutting speed has more influence in optimizing the tool wear rate.
\end{abstract}

Index Terms-Turning, titanium alloy, carbide tool, Taguchi's design methodology, tool wear, cutting fluids.

\section{INTRODUCTION}

The Titanium (Ti-6Al-4V) is an Alpha-Beta grade-5 Titanium Alloy. Higher difficulties are expected when machining Titanium alloys due to its mechanical properties especially the hardness and the tensile stress at high temperatures, differences of structure with a variable quantity of the alpha phase, morphology of the transformed beta phase, very low thermal conductivity, relatively low modulus of elasticity and high chemical reactivity with tool material. Ti-6Al-4V is the most widely used in variety of weight reduction applications such as aerospace and jet engine components; automotive and marine equipment; medical applications such as implants, turbine blades, etc. The advantages of Ti-6Al-4V alloys are less weight, high tensile strength, bio-compatibility, low thermal and electrical conductivity, corrosion resistance, etc. Cutting fluids are introduced in the machining zone to improve the tribological characteristics of machining processes to dissipate the heat generated, improving tool life, reducing work piece thermal deformation, improving surface roughness and flushing away chips from the cutting zone. The main problem associated with the machining of

Manuscript received February 14, 2014; revised April 8, 2014.

M. Venkata Ramana is with the Department of Automobile Engineering, VNR Vignana Jyothi Institute of Engg. \& Technology, Hyderabad, India (e-mail: mandalavenki@gmail.com).

G. Krishna Mohan Rao is with the Department of Mechanical Engineering, JNTUH College of Engineering, Hyderabad, India.

D. Hanumantha Rao is with the Mathrusri Engineering College, Hyderabad, India
Titanium is tool wear. It was found that the straight tungsten carbide (WC/Co) cutting tools continue to maintain their superiority machining titanium alloys [1]. The advantages of flooded/conventional use of cutting fluids in machining, however questioned lately due to their negative effects such as employee health and environmental pollution and cost. To improve the machinability of Titanium alloys, the special methods are introduced such as rotary cutting, the use of ledge tools, Minimum Quantity Lubrication (MQL) etc [1].

The cutting performance on Ti-6Al-4V alloy with synthetic oil is found to be better when compared to dry and servo cut oil with water in reducing surface roughness. The results from ANOVA shows that, while machining Ti-6Al-4V alloy, the synthetic oil is more effective under high cutting speed, high depth of cut and low feed rate compared to dry and servo cut oil with water conditions[2]. In the recent years a lot of research has been carried out to avoid the use of cutting fluids in machining. Because of them some alternatives have been sought to minimize or even avoid the use of cutting fluid in machining operations in which, one of the alternative is MQL.

The role of MQL on cutting temperature, tool wear, chip formation and product quality in turning AISI-1040 steel by uncoated carbide insert was carried out and the results are compared among dry, flooded and MQL machining. The experimental results indicate that MQL enables substantial reduction in the cutting temperature, tool wear, dimensional inaccuracy depending upon the levels of the cutting speed and feed rate [3]. Furthermore, MQL provides environment friendliness, maintaining neat, clean and dry working area, avoiding inconvenience and health hazards due to heat, smoke, fumes, gases, etc. and preventing pollution of the surroundings and improves the machinability characteristics. The optimum amount of MQL was found during machining of brass using K10 carbide tool was carried out. The Analysis of Means (ANOM) and Analysis of Variance (ANOVA) on multi-response signal-to-noise $(\mathrm{S} / \mathrm{N})$ ratio were employed for determining the optimal parameter levels and identifying the level of importance of the process parameters on surface roughness and specific cutting force [4].

The special techniques of MQL, High Pressure Coolant, Cryogenic Cooling, Compressed Air Cooling and use of Solid Lubricants/Coolants developed for turning of difficult to cut material. These techniques have resulted in reduction in friction and heat at the cutting zone, hence improved productivity of the process [5]. The MQL technique is used in turning to determine the tool wear reduction. The result 
shows that the lubricating on rake surface by the MQL technique does not produce evident of wear reduction. Tool life time of a tip used in dry cutting conditions is similar to that of a tip lubricated by MQL on the rake. Lubricating the flank surface of a tip by the MQL technique reduces the tool wear and increases the tool life. Traces of lubricant compounds have been found on the worn surfaces only when MQL has been applied on the flank surface [6].

A thorough study of literature suggests that the machining of Titanium alloy is very difficult compared to other alloy materials. Very few works have been done on the optimization of process parameters in turning process of Ti-6Al-4V alloy with different processes parameters. However very few works have carried out on machining of Titanium alloys under different lubricant conditions such as dry, flooded and Minimum Quantity Lubricant (MQL).

\section{METHODOLOGY}

In this work, Taguchi robust design methodology[7] is applied to obtain the optimum conditions for lower tool wear rate in turning of titanium Ti-6Al-4V alloy under dry, flooded and MQL conditions. Statistical software Minitab is used to obtain results for Analysis of Mean (ANOM) and Analysis of Variance (ANOVA).

\section{EXPERIMENTAL DETAILS}

The aim of this work is to find out the set of optimum values for the control factors in order to minimize tool wear rate using Taguchi's robust design methodology. The Minitab software is used to generate the linear model for ANOVA. The experiments are carried out on a GEDEEWEILER LZ350 lathe. The work piece material used is Ti-6Al-4V alloy of $120 \mathrm{~mm}$ long and $50 \mathrm{~mm}$ diameter in the form of bar.

The different types of carbide tools used in this work are made by SECO with same tool specifications. The tool holder used for machining is PSBNR16-4R174.3-2525-12 specification and it is made by sandvik coromant. Three different types of carbide tools used are uncoated grade 883, CVD coated TM 4000 and PVD coated TS 2000.

\section{A. Selection of Control Factors, Levels and Orthogonal Array}

A total of five process parameters with three levels have been chosen as the control factors such that the levels sufficiently covers wide range. The five control factors selected are type of machining environment(A), cutting speed (B), feed rate (C), depth of cut (D) and type of carbide tool material $(\mathrm{E})$. The control factors and their levels are shown in Table 1. Selection of particular Orthogonal Array (O.A) from the standard O.A. depends on the number of factors, levels of each factor, interactions and the total degrees of freedom. Based on these factors, the required minimum number of experiments to be conducted are 27 , the nearest O.A. fulfilling this condition is L27 (35) and the factors assigned to this O.A. is shown in Table II.

\section{B. Cutting Fluid/Lubricant}

The experiments are conducted under different machining environments. Fig. 1(a) shows photographic view of dry machining in which cutting fluid is not used. Fig. 1(b) shows photographic view of flooded machining. The cutting fluid used in flooded machining is GANDHAR made synthetic water soluble coolant. It contains 1: 20 volumetric concentration and flushed to the cutting zone at rate of 3 liters / min. Fig. 1(c) shows photographic view of MQL machining. MQL setup consists of air compressor, spray gun with fine nozzle and cutting fluid chamber. The cutting fluid used is same as flooded machining. Cutting fluid is supplied to spray gun at the rate of $100 \mathrm{ml} / \mathrm{hr}$, which is mixed with compressed air (3bar) in the mixing chamber of spray gun. Then the mixture of air and cutting fluid (mist) is supplied and impinged with high pressure and velocity at the cutting zone by spray gun nozzle. The mist reaches as close to the chip-tool and the work-tool interfaces as possible. The MQL spray is concentrated on rake and flank surface along the cutting edges to protect the tool faces, minimize the friction, increase the cooling, lubrication abilities and reduce the tool wear.

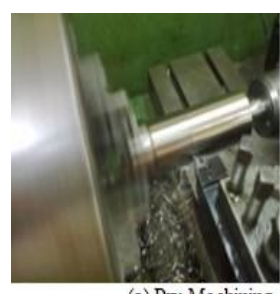

(a) Dry Machining

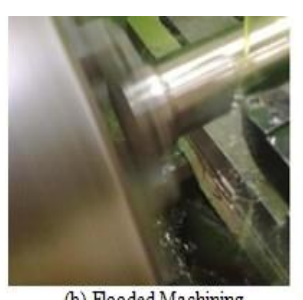

(b) Flooded Machining

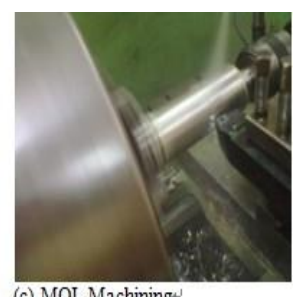

(c) MQL Machining
Fig. 1. Photographic view of turning under different machining conditions.

TABLE I: CONTROL FACTORS AND LEVELS

\begin{tabular}{|c|c|c|c|c|c|}
\hline $\begin{array}{c}\text { Factors/ } \\
\text { Levels }\end{array}$ & $\begin{array}{c}\text { Type of } \\
\text { machining } \\
\text { environment } \\
(\mathbf{A})\end{array}$ & $\begin{array}{c}\text { Speed } \\
(\mathbf{B}) \\
(\mathbf{m} / \mathbf{m i n})\end{array}$ & $\begin{array}{c}\text { Feed } \\
\text { rate }(\mathbf{C}) \\
(\mathbf{m m} / \mathbf{r e v})\end{array}$ & $\begin{array}{c}\text { Depth } \\
\text { of } \\
\text { Cut(D) } \\
(\mathbf{m m})\end{array}$ & $\begin{array}{c}\text { Type of } \\
\text { Tool } \\
\text { Material } \\
(\mathbf{E})\end{array}$ \\
\hline 1 & Dry & $63(\mathrm{~B} 1)$ & $\begin{array}{c}0.206 \\
(\mathrm{C} 1)\end{array}$ & $\begin{array}{c}0.6 \\
(\mathrm{D} 1)\end{array}$ & $\begin{array}{c}\text { Uncoated } \\
(\mathrm{E} 1)\end{array}$ \\
\hline 2 & Flooded & $79(\mathrm{~B} 2)$ & $\begin{array}{c}0.274 \\
(\mathrm{C} 2)\end{array}$ & $\begin{array}{c}1.0 \\
(\mathrm{D} 2)\end{array}$ & $\begin{array}{c}\text { CVD } \\
\text { Coated } \\
(\mathrm{E} 2)\end{array}$ \\
\hline 3 & $\mathrm{MQL}$ & $99(\mathrm{~B} 3)$ & $\begin{array}{c}0.343 \\
(\mathrm{C} 3)\end{array}$ & $\begin{array}{c}1.6 \\
(\mathrm{D} 3)\end{array}$ & $\begin{array}{c}\text { PVD } \\
\text { Coated } \\
(\mathrm{E} 3)\end{array}$ \\
\hline
\end{tabular}

\section{Experimental Procedure}

Titanium specimens are prepared for conduct of the experiments. The specimens have turned on lathe according to L27 Orthogonal Array (O.A) as shown in Table II under dry, flooded and MQL conditions. The tool makers microscope is used to measure flank wear on cutting tool for each experiment as shown in Fig. 2. The summary of average tool wear rate and its $\mathrm{S} / \mathrm{N}$ ratio of flank wear are shown in Table II. Optimization of process parameters is carried out using Taguchi Robust design methodology and statistical Minitab software [7], [8]. Tool wear is measured by observing and measuring the wear as it develops. The flank wear is generally measured from the original cutting edge. If the flank wear is not uniform along the flank face, the mean value tool wear (VB) is determined.

\section{EXPERIMENTAL RESULTS AND DISCUSSIONS}

In this work, the performance characteristics namely tool wear has to be reduced and hence "smaller the better type" quality characteristic has been selected. The $\mathrm{S} / \mathrm{N}$ ratio 
associated with this characteristic is shown in equation (1)

Smaller the better:

$$
S / N=-10 \log \left(\frac{1}{n} \sum_{i=1}^{n} y_{i}^{2}\right)
$$

where $y$ is the observed data.

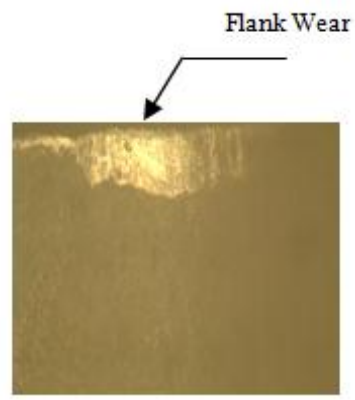

Fig. 2. Flank wear on uncoated carbide cutting tool.

\section{A. Optimization of Cutting Parameters}

To arrive optimum process parameters, Taguchi's robust design methodology has been successfully employed in order to minimize the tool wear. After analysis of data from the robust design of experiments, the optimum process parameters found. The mean effect plot for tool wear is shown in Fig. 3. The condition for the optimum level is the maximum $\mathrm{S} / \mathrm{N}$ ratio. It is observed that, the MQL is found to be optimum compared to dry and flooded conditions and uncoated tool is found to be optimum compared to CVD and PVD coated tools. The average value of the performance characteristic for each parameter is referred as mean response at different levels. Thus, the optimal process parameters obtained are MQL machining environment (A3), cutting speed at $63 \mathrm{~m} / \mathrm{min}$ (B1), feed rate at 0.274 $\mathrm{mm} / \mathrm{rev}$. ( C2), depth of cut at $1.0 \mathrm{~mm}$ (D2) and uncoated tool (E1) levels.

TABLE II: L27 ORTHOGONAL ARRAY WITH TOOL WEAR AND S/N RATIO

\begin{tabular}{|c|c|c|c|c|c|c|c|}
\hline S.No & A & B & C & D & E & VB & S/N ratio \\
\hline $\mathbf{1}$ & Dry & B1 & F1 & D1 & T1 & 0.080 & 21.87 \\
\hline $\mathbf{2}$ & Dry & B1 & F2 & D2 & T2 & 0.075 & 22.47 \\
\hline $\mathbf{3}$ & Dry & B1 & F3 & D3 & T3 & 0.095 & 20.33 \\
\hline $\mathbf{4}$ & Dry & B2 & F1 & D2 & T3 & 0.090 & 20.86 \\
\hline $\mathbf{5}$ & Dry & B2 & F2 & D3 & T1 & 0.095 & 20.43 \\
\hline $\mathbf{6}$ & Dry & B2 & F3 & D1 & T2 & 0.110 & 19.17 \\
\hline $\mathbf{7}$ & Dry & B3 & F1 & D3 & T2 & 0.210 & 13.55 \\
\hline $\mathbf{8}$ & Dry & B3 & F2 & D1 & T3 & 0.115 & 18.77 \\
\hline $\mathbf{9}$ & Dry & B3 & F3 & D2 & T1 & 0.115 & 18.77 \\
\hline $\mathbf{1 0}$ & Flooded & B1 & F1 & D1 & T1 & 0.055 & 25.15 \\
\hline $\mathbf{1 1}$ & Flooded & B1 & F2 & D2 & T2 & 0.065 & 23.71 \\
\hline $\mathbf{1 2}$ & Flooded & B1 & F3 & D3 & T3 & 0.080 & 21.87 \\
\hline $\mathbf{1 3}$ & Flooded & B2 & F1 & D2 & T3 & 0.080 & 21.93 \\
\hline $\mathbf{1 4}$ & Flooded & B2 & F2 & D3 & T1 & 0.070 & 23.01 \\
\hline $\mathbf{1 5}$ & Flooded & B2 & F3 & D1 & T2 & 0.085 & 21.39 \\
\hline $\mathbf{1 6}$ & Flooded & B3 & F1 & D3 & T2 & 0.190 & 14.41 \\
\hline $\mathbf{1 7}$ & Flooded & B3 & F2 & D1 & T3 & 0.070 & 23.01 \\
\hline $\mathbf{1 8}$ & Flooded & B3 & F3 & D2 & T1 & 0.085 & 21.39 \\
\hline $\mathbf{1 9}$ & MQL & B1 & F1 & D1 & T1 & 0.060 & 24.43 \\
\hline $\mathbf{2 0}$ & MQL & B1 & F2 & D2 & T2 & 0.060 & 24.31 \\
\hline $\mathbf{2 1}$ & MQL & B1 & F3 & D3 & T3 & 0.075 & 22.47 \\
\hline $\mathbf{2 2}$ & MQL & B2 & F1 & D2 & T3 & 0.065 & 23.71 \\
\hline $\mathbf{2 3}$ & MQL & B2 & F2 & D3 & T1 & 0.060 & 24.31 \\
\hline $\mathbf{2 4}$ & MQL & B2 & F3 & D1 & T2 & 0.105 & 19.56 \\
\hline $\mathbf{2 5}$ & MQL & B3 & F1 & D3 & T2 & 0.180 & 14.88 \\
\hline $\mathbf{2 6}$ & MQL & B3 & F2 & D1 & T3 & 0.075 & 22.47 \\
\hline $\mathbf{2 7}$ & MQL & B3 & F3 & D2 & T1 & 0.095 & 20.43 \\
\hline
\end{tabular}

\section{B. Interaction Effect of Process Parameters on Tool Wear}

The interaction effects between two factors on $\mathrm{S} / \mathrm{N}$ ratio are examined to determine the relative importance of the parameters on tool wear portion under different coolant conditions. Fig. 4 shows the interaction plots between cutting speed and type of coolant condition. Under dry condition, the effect of cutting speed on tool wear from 63 to $79 \mathrm{~m} / \mathrm{min}$ and 79 to $99 \mathrm{~m} / \mathrm{min}$ is maximum. Similarly under flooded and MQL conditions the effect of cutting speed on tool wear from 63 to $79 \mathrm{~m} / \mathrm{min}$ and 79 to $99 \mathrm{~m} / \mathrm{min}$ is maximum. As seen from Fig. 4, as the machining environment changes, $\mathrm{S} / \mathrm{N}$ ratios increases from dry to flooded and flooded to MQL. This indicates that the tool wear decreases from dry to flooded and flooded to MQL. Hence, reduction of tool wear is observed in MQL compared to dry and flooded machining.

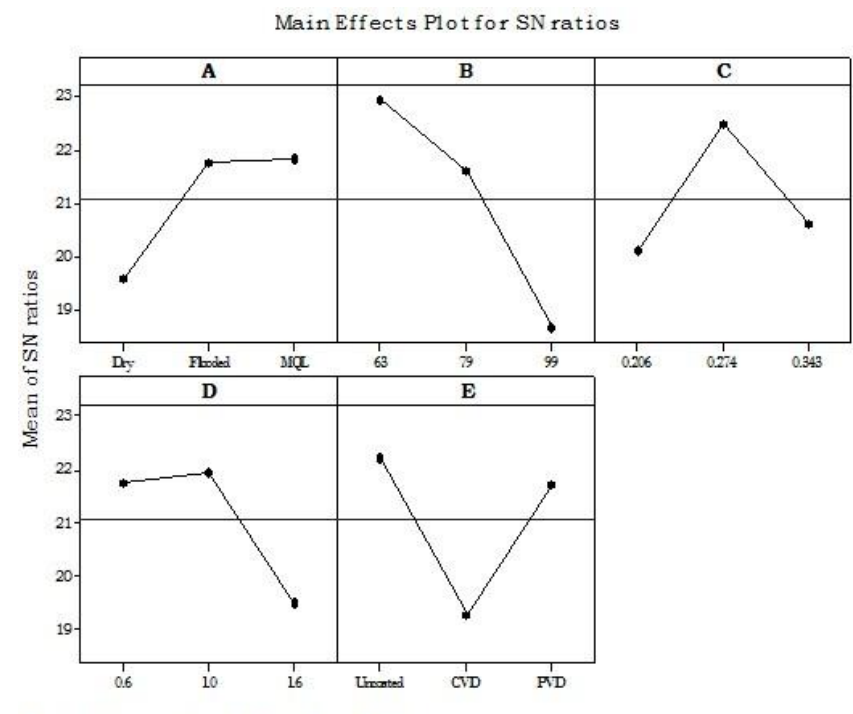

Signal-to-noise: Smaller is better

Fig. 3. Main effect plots for tool wear.

Fig. 5 shows the interaction plots between feed rate and type of coolant condition. Under dry condition, the effect of feed rate on tool wear from 0.206 to $0.274 \mathrm{~mm} / \mathrm{rev}$ is maximum and 0.274 to $0.343 \mathrm{~m} / \mathrm{min}$ is minimum. Similarly under flooded condition the effect of feed rate on tool wear from 0.206 to $0.274 \mathrm{~mm} / \mathrm{rev}$ is maximum and 0.274 to 0.343 $\mathrm{m} / \mathrm{min}$ is minimum and under MQL condition the effect of feed rate on tool wear from 0.206 to $0.274 \mathrm{~mm} / \mathrm{rev}$ and 0.274 to $0.343 \mathrm{~m} / \mathrm{min}$ are maximum. As seen from Fig. 5 , as the machining environment changes, $\mathrm{S} / \mathrm{N}$ ratios increases from dry to flooded and flooded to MQL. This indicates that the tool wear decreases from dry to flooded and flooded to MQL expect feed rate at $0.343 \mathrm{~mm} / \mathrm{rev}$. Hence, it is observed the tool wear is less in MQL compared to dry and flooded machining.

Fig. 6 shows the interaction plots between depth of cut and type of coolant condition. Under dry condition, the effect of depth of cut on tool wear from 0.6 to $1.0 \mathrm{~mm}$ is minimum and 1.0 to $1.6 \mathrm{~m} / \mathrm{min}$ is maximum. Similarly under flooded condition the effect of depth of cut on tool wear from 0.6 to $1.0 \mathrm{~mm}$ is minimum and 1.0 to $1.6 \mathrm{~mm}$ is maximum and under MQL condition the depth of cut on tool wear from 0.6 to $1.0 \mathrm{~mm} / \mathrm{rev}$ is minimum and 1.0 to 1.6 $\mathrm{m} / \mathrm{min}$ is maximum. As seen from Fig. 6, as the machining environment changes, $\mathrm{S} / \mathrm{N}$ ratios increases from dry to 
flooded and flooded to MQL. This indicates that the tool wear decreases from dry to flooded and flooded to MQL expect depth of cut at $0.6 \mathrm{~mm}$. Therefore, compare to dry and flooded, with MQL machining tool wear is less.

Fig. 7 shows the interaction plots between type of tool material and coolant condition. Under dry condition, the effect and change of tool material on tool wear from uncoated to CVD and CVD to PVD is maximum. Similarly under flooded condition the effect and change of tool material on tool wear from uncoated to CVD and PVD to CVD is maximum and under MQL condition effect and change of tool material on tool wear from uncoated to CVD and PVD to CVD is maximum. From Fig. 7, it also indicates that, change of tool material on tool wear from uncoated to PVD is minimum. As seen from Fig. 7, as the machining environment changes, $\mathrm{S} / \mathrm{N}$ ratios increases from dry to flooded and flooded to MQL in the case PVD tool. This indicates that the tool wear decreases from dry to flooded and flooded to MQL. Whereas, as the machining environment changes, $\mathrm{S} / \mathrm{N}$ ratios increases from dry to flooded and decreases from flooded to MQL. This indicates that the tool wear decreases from dry to flooded and increases from flooded to MQL.

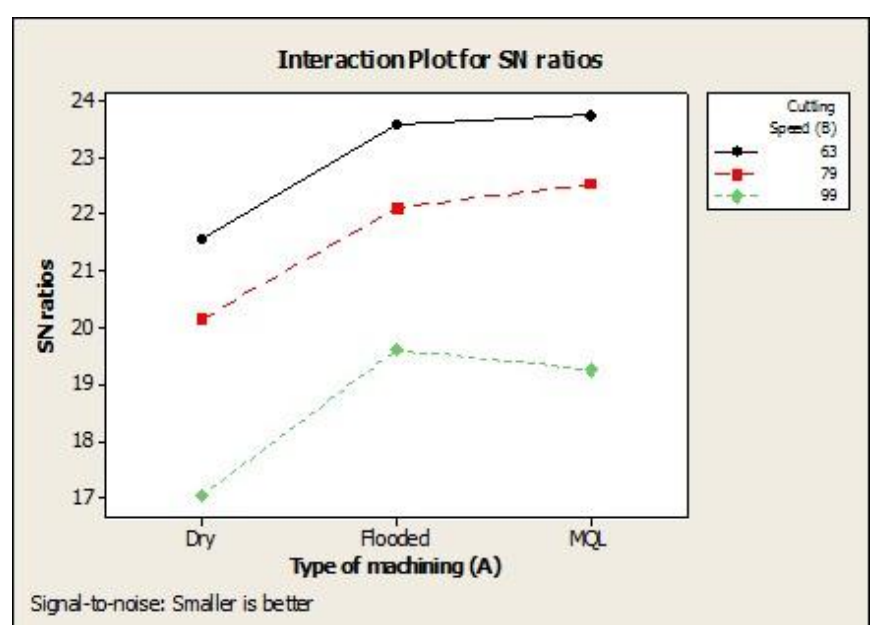

Fig. 4. Interaction effect plot of cutting speed and type of coolant.

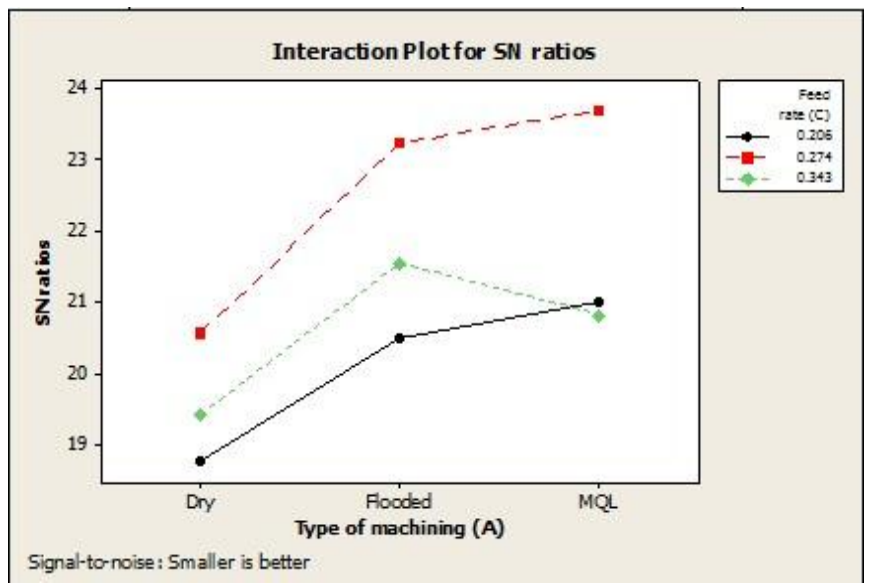

Fig. 5. Interaction effect plot of feed rate and type of coolant.

\section{Influence of Process Parameters}

Analysis of Variance is carried out to evaluate influence and performance of each process parameter in machining. The results of ANOVA on performance characteristic are shown Table III. The P-value in Table III indicates the significant condition of each factor. As seen from ANOVA Table III to minimize the tool wear, cutting speed has highly responsive $(35.165 \%)$ in optimizing the performance characteristics followed by tool material, depth of cut, feed rate and coolant condition.

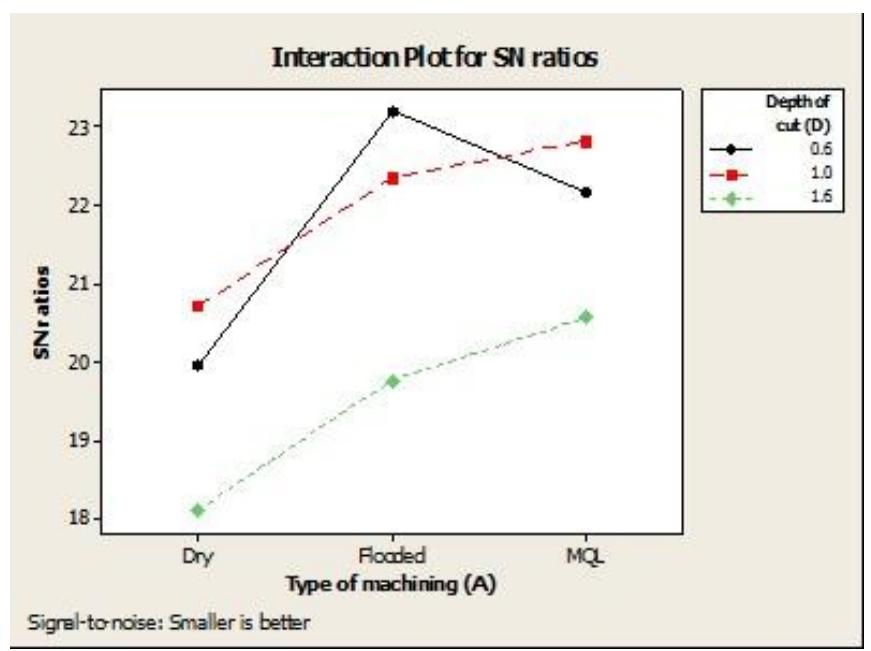

Fig. 6. Interaction effect plot of depth of cut and type of coolant.

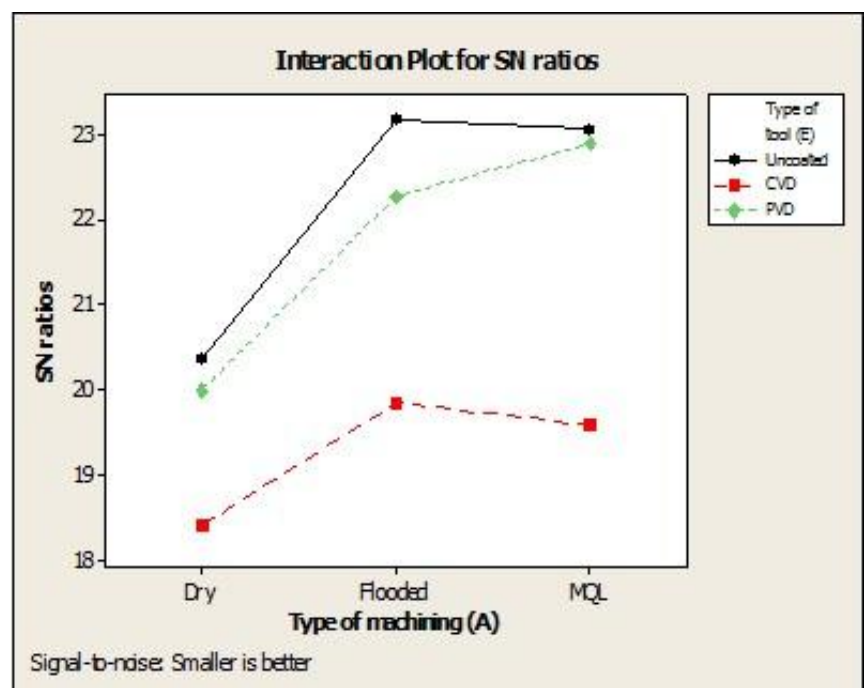

Fig. 7. Interaction effect plot of type of tool material and type of coolant.

The error contribution $3.49 \%$ is observed from ANOVA. Further the interaction between type of coolant condition with cutting speed, feed rate, depth of cut and tool material are insignificant and shown in Table III with bold letters. The predictive or additive model is developed using optimum conditions of the $\mathrm{S} / \mathrm{N}$ ratio as shown in Eq. (2).

$$
\begin{aligned}
\eta_{\text {predicted }}=Y+(A 3-Y) & +(B 1-Y)+(C 2-Y)+(D 2-Y) \\
+ & (E 1-Y)
\end{aligned}
$$

where $Y$ is average $S / N$ ratio; $A 3, B 1, C 2, D 2$ and $E 1$ are optimum cutting parameter. The predicted $S / \mathrm{N}$ ratio is 27.79 $\mathrm{dB}$. The verification test results must be confirmed to the predicted results. Hence with the optimum conditions, the verification experiment is conducted and corresponding $\mathrm{S} / \mathrm{N}$

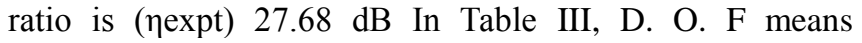
Degrees of Freedom, S.S means Sum of Squares, P means Predicted value (If the predicted value of a factor is $<0.05$ then the factor is said to be significant). This analysis is carried out at a significant level of 5\% and confidence level of $95 \%$. 
TABLE III: SUMMARY OF ANOVA ON TOOL WEAR

\begin{tabular}{|c|c|c|c|l|l|l|l|}
\hline Factors(Source) & S.S & D.O.F & M.S.S & F-RATIO & SS $^{\mathbf{1}}$ & P-Value $^{\prime} \boldsymbol{\rho} \%$ \\
\hline Type of machining environment (A) & 0.00638 & 2 & 0.00319 & 29.71 & 0.00638 & 0 & 7.6899 \\
\hline Cutting speed (B) (mpm) & 0.02918 & 2 & 0.01459 & 135.84 & 0.02918 & 0 & 35.165 \\
\hline Feed rate (C) (mm/rev) & 0.01174 & 2 & 0.00587 & 54.64 & 0.01174 & 0 & 14.144 \\
\hline Depth of cut(D) (mm) & 0.01454 & 2 & 0.00727 & 67.67 & 0.01454 & 0 & 17.518 \\
\hline Type of Tool (E) & 0.01825 & 2 & 0.00912 & 84.95 & 0.01825 & 0 & 21.99 \\
\hline $\mathbf{A}^{* \mathbf{B}}$ & $\mathbf{0 . 0 0 0 4 1}$ & 4 & 0.0001 & 0.95 & 0.00041 & $\mathbf{0 . 4 5 1}$ & \\
\hline $\mathbf{A}^{* \mathbf{C}}$ & $\mathbf{0 . 0 0 0 5 5}$ & 4 & 0.00014 & 1.28 & 0.00055 & $\mathbf{0 . 3 0 1}$ & \\
\hline $\mathbf{A}^{* \mathbf{D}}$ & $\mathbf{0 . 0 0 0 6 9}$ & 4 & 0.00017 & 1.59 & 0.00069 & $\mathbf{0 . 2 0 4}$ & \\
\hline $\mathbf{A}^{*} \mathbf{E}$ & $\mathbf{0 . 0 0 0 2 7}$ & 4 & $6.9 \mathrm{E}-05$ & 0.64 & 0.00027 & $\mathbf{0 . 6 4}$ & \\
\hline Error & 0.0029 & 27 & 0.00011 & & 0.0029 & & 3.4946 \\
\hline Total & 0.0849 & 53 & & & & & \\
\hline Total After excluding insignificant (Bold letters) & 0.08299 & & & & & & 100 \\
\hline factors & & & & & & \\
\hline
\end{tabular}

\section{Regression Analysis}

The Mathematical predictive model is to developed with help of multiple regression analysis using the predictors' viz. Type of machining environment, cutting speed, feed rate, depth of cut and type of carbide tool materials. The statistical tool Minitab is used to develop predictive models for tool wear.

After Regression analysis, the final second order regression model is given by:

$$
\begin{array}{r}
V B=0.591-0.00444 \times X 1+0.0178 \times X 2-0.00340 \times V c- \\
3.07 \times F-0.09318 \times D+0.0378 \times Y 1-0.00444 \times Y 2+ \\
5.34 \times F \times F+0.0565 \times D \times D+0.000031 \times V c \times V c
\end{array}
$$

where $V B=$ Tool wear rate; $V c=$ cutting speed; $F=$ feed rate; $D=$ depth of cut; and $X 1, X 2$ and $Y 1, Y 2$ are the indicator variables of type of machining environment and tool materials respectively.

\section{CONCLUSIONS}

Based on the results of these experimental investigations, the following conclusions are drawn:

- The machining performance of MQL machining shows favorable and better results compared to dry and flooded conditions.

- The MQL machining shows advantage mostly by reducing tool wear as well as environmental problems, which reduces the friction between the chip - tool interaction.

- The optimal process parameters for minimizing tool wear are MQL machining environment, cutting speed at $63 \mathrm{~m} / \mathrm{min}$, feed rate at $0.274 \mathrm{~mm} / \mathrm{rev}$, depth of cut at $1.0 \mathrm{~mm}$ and uncoated tool.

- Using ANOVA, the effect each individual factors on tool wear found to be significance and the contribution of cutting speed is more followed by tool material, depth of cut, feed rate and coolant condition in order to minimizing tool wear.
- The confirmation experiments are revealed that Taguchi's robust design methodology is successfully verified with the optimum process parameters. The predicted model is adequate at $95 \%$ confidence level with confirmation experiment chosen for optimum quality characteristics.

- The mathematical model is developed using Multiple Regression Analysis and this model is verified successfully with experimental results.

\section{REFERENCES}

[1] E. O. Ezugwu, Z. M. Wang, "Titanium alloys and their machinabilitya review," Journal of Materials Processing Technology, 1997, 68: 262-274.

[2] M. V. Ramana, G. K. M. Rao, and D. H. Rao, "Experimental investigations and selection of optimal cutting conditions in turning of Ti-6Al-4V alloy with different cutting fluids by minimum quantity lubrication methodology," I-Manager's Journal On Mechanical Engineering, vol. 2, pp. 44-51, 2011.

[3] N. R. Dhar, M. W. Islam, S. Islam, and M. A. H. Mithu, "The influence of MQL on cutting temperature, chip and dimensional accuracy in turning AISI-1040 steel," Jl. of Materials Proc. Tech., 2006, vol. 171, pp. 93-99.

[4] V. N. Gaitonde, S. R. Karnik, and J. Paulo Davim, "Selection of optimal MQL and cutting conditions for enhancing machinability in turning of brass," Journal of Materials Processing Technology, vol. 204, pp. 459-464, 2008.

[5] V. S. Sharma, M. Dogra, and N. M. Suri, "Cooling techniques for improved productivity in turning," International Journal of Machine Tools \& Manufacture, vol. 49, pp. 435-453, 2009.

[6] A. Attanasio, "Minimal quantity lubrication in turning: Effect on tool wear," Wear, vol. 60, pp. 333-338, 2005.

[7] P. J. Ross, Taguchi Techniques for Quality Engineering, Tata McGraw Hill, 2005.

[8] Minitab Statistical Software Features - Minitab, Software for Statistics, Process Improvement, Six Sigma, Quality, Minitab, 2011.

[9] C. M. Douglas, A. P. Elizabeth, and G. Geoffrey, Intd. to Linear Regression Analysis, Arizona State Uni., 2001.

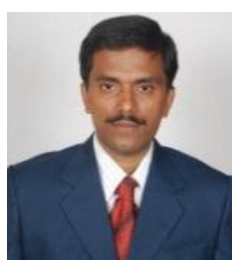

M. Venkataramana is an associate professor in the Department of Automobile Engineering at VNR Vignana Jyothi Institute of Engg \& Tech, Hyderabad, India. $\mathrm{He}$ is presently pursuing Ph.D., in manufacturing area. He has published in peer reviewed 02 international \& 01 national journal, 04 International and 10 national conferences papers. 
G. Krishna Mohana Rao is a professor of Mechanical Engineering Department at JNTUH, Hyderabad and member of ASME, ISTE, IE(I). He has published 40 papers in international journals and conferences. He co-authored a book on engg. mechanics published by Pearson education. He visited various counties for presenting papers in international conferences.

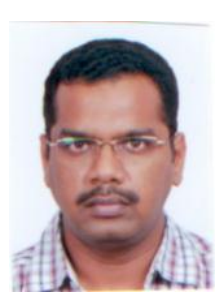

D. Hanumantha Rao is presently working as the principal at Matrusri Engineering College, Saidabad, Hyderabad, India. He has more than twenty six years experience in industry, teaching, research and development in Mechanical Engineering. He has more than thirty publications in national, international journals and conferences. 